University of Nebraska - Lincoln

DigitalCommons@University of Nebraska - Lincoln

Faculty Publications, Department of Psychology

Psychology, Department of

December 2004

\title{
Parental Beliefs Regarding Developmental Benefits of Childhood Injuries
}

\author{
Terri Lewis \\ University of North Carolina, Chapel Hill, terri.lewis@mail.cscc.unc.edu \\ David DiLillo \\ University of Nebraska-Lincoln, ddilillo@unl.edu \\ Lizette Peterson \\ University of Missouri-Columbia
}

Follow this and additional works at: https://digitalcommons.unl.edu/psychfacpub

Part of the Psychiatry and Psychology Commons

Lewis, Terri; DiLillo, David; and Peterson, Lizette, "Parental Beliefs Regarding Developmental Benefits of Childhood Injuries" (2004). Faculty Publications, Department of Psychology. 127.

https://digitalcommons.unl.edu/psychfacpub/127

This Article is brought to you for free and open access by the Psychology, Department of at DigitalCommons@University of Nebraska - Lincoln. It has been accepted for inclusion in Faculty Publications, Department of Psychology by an authorized administrator of DigitalCommons@University of Nebraska - Lincoln. 


\title{
Parental Beliefs Regarding Developmental Benefits of Childhood Injuries
}

\author{
Terri Lewis, PhD; David DiLillo, PhD; Lizette Peterson,PhD
}

Objective: To assess parental beliefs that minor childhood injuries play a beneficial role in the development of young children. Methods: Mothers and fathers of 159 children, ages 15 to 40 months, completed the Injury Attitudes Questionnaire (IAQ), designed to assess parental beliefs that children "learn from" and "toughen up" as a result of experiencing minor injuries. Results: A main effect for parent gender was found such that fathers endorsed stronger beliefs than did mothers regarding the developmental benefits of injuries. Conclusions: The accuracy of these beliefs as well as their relevance to parental injury-prevention behaviors is discussed.

Key words: injury, children, attitudes

Am J Health Behav. 2004;28(Suppl 1):S61-\$68
$\mathrm{T}$ The popularity of colloquialisms such as "what doesn't kill you makes you stronger," "no pain, no gain," and, "once burned, twice shy" suggests a widespread societal belief that exposure to some types of physiological or psychological stressors may in some way be beneficial to the individuals who experience them. Implied by these aphorisms is the notion that enduring a hardship may sometimes promote the development of improved emotional strength, physical strength, or resilience to future harm. Several examples from the psychological literature suggest that such beliefs are

Terri Lewis, Statistician, Collaborative Studies Coordinating Center, Department of Biostatistics, University of North Carolina, Chapel Hill, NC. David DiLillo, Assistant Professor, Department of Psychology, University of Nebraska-Lincoln, Lincoln, NE. Lizette Peterson, University of Missouri-Columbia, Dr Peterson passed away in July 2002.

Address correspondence to Dr Lewis, Department of Biostatistics, Collaborative Studies Coordinating Center, 203 Bank of America Plaza, CB\# 8030, University of North Carolina, Chapel Hill, NC 27599. 8030.E-mail:UCCTLL@MAIL.CSCC.UNC.EDU not without some merit. It has been theorized, for instance, that physical and social stressors may lead to a "toughening" of the sympathetic nervous system, which may in turn have psychological and physical benefits such as increased stress tolerance, physical endurance, and reduced susceptibility to diseases. ${ }^{1}$ Similarly, some behavior therapies (eg, systematic desensitization) are predicated on the notion that controlled, incremental exposure to a stressor can result in improved emotional and behavioral coping during future encounters with similar stressors. Even individuals with a history of sexual victimization have reported positive outcomes associated with their abusive experiences, such as improved self-protection, increased compassion for victims, and a stronger personality. ${ }^{2}$

The notion that negative experiences can lead to positive outcomes may be applicable to other types of stressors as well. In the area of pediatric injury, for example, many adult caregivers may believe that minor injuries, though undesirable, are a natural consequence of careless or inattentive behavior on the part of children. Further, adult respondents often consider injuries to be the 
fault of the victim, citing inappropriate or clumsy behavior as the cause. ${ }^{3}$ Caregivers may adopt similar attitudes about the causes of childhood injuries, with the added belief that such events serve a developmental function by "teaching children a lesson" that certain behaviors or situations are dangerous and should be avoided in the future. ${ }^{4}$ From an operant conditioning perspective, this line of reasoning appears quite plausible, in that the pairing of risky behavior with the pain and discomfort of a minor injury might be expected to result in a future decrease in the frequency of that same risk behavior. Thus, a child who unintentionally cuts him-or herself with a kitchen knife would learn not to play with knives again.

In addition to believing in the teaching value of minor injuries, caregivers may also subscribe to the logical but as yet unsupported notion that injuries will "toughen up" children. That is, parents may view minor injury events as character-building experiences with the potential to promote mental or physical "toughness," pain tolerance, or improved coping in the face of future injuries or physical discomfort. Hence, a child who falls and bruises a knee may be encouraged by a parent to "walk it off," under the assumption that a minor injury will help the child learn to cope more effectively with future pain or discomfort.

If parents in general hold these beliefs, then fathers may more strongly endorse the notion that injuries can help children toughen up or learn safe behaviors. The parenting literature documented early on that fathers spend a greater proportion of time with their children engaged in vigorous physical activities, whereas mothers are more likely to interact with children through the performance of basic caregiving behaviors (eg, feeding, bathing) ${ }^{5,6}$ These contrasting parenting styles may, to some degree, be accompanied by differential beliefs concerning the value and impact of minor injuries. For example, it may be that fathers' preferences for physical play with children are indicative of less overall concern about the risk of minor injuries, as well as a greater belief that injuries have the potential to help children learn about risk or toughen them up.

Seminal literature assessing parental socialization of children has also docu- mented that both mothers and fathers tend to treat sons and daughters differently and that fathers do so to an even greater extent than mothers. ${ }^{7}$ For example, both parents, but especially fathers, encourage boys to take part in physically vigorous activities, whereas girls are encouraged to participate in activities that are less active and physically risky. ${ }^{8}$ More specific to injury, parents have been found to view risk taking as more normative for boys (ie, resulting from inborn characteristics), whereas the same behaviors for girls may be attributed to carelessness or inattention to safety. ${ }^{4}$ Based on this work suggesting a greater acceptance of physical risk taking among boys than girls, we hypothesized that both parents might ascribe greater benefits to injuries sustained by sons than by daughters and that fathers would do so to a greater extent than mothers.

Parental attitudes about the value of unintentional injuries may have important implications for children's physical health and well-being. More than 14 million children are injured every year, ${ }^{9}$ making injuries the leading cause of death and disability for those between the ages of 1 and 21 in the United States. ${ }^{10}$ Because young children must rely on adult caregivers for protection and physical safety, parental attitudes about the outcomes of such events may have a bearing upon the injury risk to which children are exposed. If parents feel that injuries teach children safe behaviors or bolster resilience to future harm, they may be less inclined to take steps that will effectively minimize the many potentially hazardous situations children encounter on a daily basis. Conversely, caregivers who perceive no developmental benefits associated with injuries may be more vigilant in attending to the risks faced by their children.

The purpose of this study was to provide an initial exploration of parental attitudes about the developmental benefits of minor injuries. Injury attitudes were assessed with the Injury Attitudes Questionnaire (IAQ), a self-report instrument developed for this study to measure beliefs in 2 specific areas: the learning value and "toughening up" characteristics of minor injuries. Given greater parental acceptance of risky behaviors for boys and fathers' preferences for engaging in rough and tumble play with 
children, we were particularly interested in whether injury beliefs might vary as a function of parent and/or child gender or an interaction of parent and child gender. Knowledge gained from this study may help to identify potential points of intervention for preventive efforts targeting caregivers of young children.

\section{METHOD}

\section{Participants}

One hundred fifty-nine families from a midsized Midwestern city served as participants in the study. All families taking part in the project had a child between 15 and 40 months of age $(M=25.11, S D=$ 7.79). Families with toddlers were selected because children this age are more likely to be influenced by parental attitudes and beliefs than are school-aged children, who may also be influenced by peers or classmates. Participants were part of a larger ongoing study assessing risk factors associated with unintentional childhood injuries. ${ }^{11}$ Participants from the larger study were recruited from the following sources: (a) a local family practice group, (b) local community newspaper, and (c) referrals from parents already participating in the study. Interested participants were screened by phone to ensure that they met several eligibility requirements. These requirements were that (a) English was the primary language of the biological parent, (b) the target child had never been hospitalized overnight for an injury, and (c) the target child did not have any known mental, physical, or developmental disabilities. Parents from the larger study were asked to record detailed information about the circumstances of each injury their child sustained over a 6 -month period. Parents were also asked to complete measures assessing child, family, and parent characteristics.

Parents participating in the current study were predominately white $(91 \%)$, with fewer African American (4\%), Asian American (1\%), or Hispanic parents $(1 \%)$. Two percent of parents indicated their ethnicity was something other than those represented above. Parents were fairly well educated, with the majority having obtained at least a college degree $(68 \%$ of mothers and $64 \%$ of fathers). Eighty-eight percent of households were dual-parent households. Families reported a range of incomes with $34 \%$ earning less than $\$ 25,000,53 \%$ earning between $\$ 25,000$ and $\$ 55,000$, and $26 \%$ earning more than $\$ 55,000$ annually. The mean age for mothers was 28.82 (SD $=4.42$ ) and for fathers, $31.32(\mathrm{SD}=5.32)$. Of the 159 families who participated, 23 families had reports from mothers only and 2 families had reports from fathers only (total sample size $=293$ ). Analyses comparing mother and father reports were restricted to the 134 cases in which both parents' reports were available. In order to assess test-retest reliability of subject responses, a subsample of the first 46 mothers and 32 fathers (29\% and $24 \%$ of mothers and fathers respectively) who enrolled in the study completed the measure a second time, approximately 2 weeks following the first administration.

\section{Measures}

Injury Attitudes Questionnaire (IAQ). Participants were asked to indicate their level of agreement to 30 statements on a 7 -point Likert scale $(1=$ very strongly disagree to $7=$ very strongly agree). These statements reflected a range of possible parental attitudes regarding childhood injuries. Although the entire pool of 30 items was initially subjected to an exploratory factor analysis, several of the items did not load well and the procedure did not yield conceptually meaningful constructs. Therefore, based on conceptual similarities, the subset of 14 items that appeared most likely to encompass the hypothesized constructs (ie, toughening and learning) were chosen from the original item pool for additional factor analysis. A principal-factors approach with an oblique rotation yielded a 2 -factor solution based on the Kaiser Criterion (eigenvalues for the first 5 factors were $5.14,1.17, .52, .23$, and .11). Factor 1 included items consistent with the notion that injuries help children endure physical or emotional pain. Factor 2 consisted of items related to the educational benefits of injury. The correlation between the 2 factors was .55 . Items were retained if the factor loading was at least .4 (see Table 1 for item loadings). Two scores were generated for each respondent by averaging the responses of items corresponding to each factor. These scores are hereafter referred to as the Toughening subscale and the Learning subscale.

A total injury attitude score was also generated by averaging the responses to all 14 items. Scores from the 2 subscales 


\section{Table 1}

\section{Summary of Factor Loadings for an Oblique 2-Factor Solution for the Injury Attitudes Questionnaire}

\section{Factor 1. Toughening}

4. Being injured may help my child "toughen" up mentally.

8. Being injured may help my child "toughen up" physically.

$.86-.02$

.85

.83

1. Injuries can help my child learn to handle physical pain better.

2. Minor injuries can sometimes help my child build character and stamina.

7. When it comes to my child, I believe the saying "No pain, no gain". or "wuss" as an adult.

\section{Factor 2. Learning}

13. My child's injury experiences help him/her learn the consequences of risky behavior.

11. When it comes to my child, I believe that the "once burned, twice shy" notion is correct.

3. A few minor injuries could be good for my child, because they can help him/her learn to be more cautious.

5. Experiencing a few minor injuries may help my child prepare better for life by teaching him/her how injuries occur and can be avoided.

12. After being injured, my child usually leams not to do the same thing again.

14. Getting injured can help my child learn the limits of his/her physical abilities.

6. Sometimes it is better to let my child learn on his/her own, even if it means getting hurt a little.

10. My child can build character by taking sensible risks that could result in some and the total score were used for all subsequent analyses.

\section{Procedures}

Mothers and fathers completed the questionnaires in their homes as part of an ongoing study assessing risk factors associated with unintentional childhood injuries. Paid research assistants delivered and received the completed questionnaires during biweekly meetings with mothers, at which time they were available to answer questions and clarify directions. Written informed consent was obtained from parents at the beginning of the larger study and included information regarding the completion of several questionnaires relevant to the study objectives, which included the IAQ. Approval for the project was granted by the University of Missouri Institutional Review Board.

\section{RESULTS}

Analyses were centered on 2 main goals: to determine the internal consistency and test-retest reliability of the IAQ and to examine the effect of parent and child gender on responses to the IAQ.

\section{Reliability}

The internal reliability for the IAQ, collapsed across mother and father reports, was calculated using coefficient $\alpha$. Results indicated high internal consistency for the Learning subscale $(\alpha=.80)$, the Toughening subscale $(\alpha=.88)$, and the total score $(\alpha=.88)$. Interitem correlations ranged from .12 to .65 for the Learning subscale, and .37 to .74 for the Toughening subscale, and .06 to .74 for the total score.

Test-retest reliability was calculated by computing correlations between the first and second administrations of the questionnaire for the 78 participants who completed both administrations. Testretest reliability coefficients for the Learning and Toughening subscales, collapsed 


\section{Table 2 \\ Mean Responses for Mothers and Fathers for Each Item on the Injury Attitudes Questionnaire}

\begin{tabular}{|c|c|c|}
\hline Items and Subscales & $\begin{array}{c}\text { Mother } \\
\text { Responses } \\
\text { M (SD) }\end{array}$ & $\begin{array}{c}\text { Father } \\
\text { Responses } \\
\text { M (SD) }\end{array}$ \\
\hline \multicolumn{3}{|l|}{ Toughen Subscale } \\
\hline 1. Injuries can help my child learn to handle physical pain better. & $2.77(1.71)$ & $3.77(1.81)$ \\
\hline 2. Minor injuries can sometimes help my child build character and stamina. & $3.02(1.72)$ & $3.70(1.81)$ \\
\hline 3. Being injured may help my child "toughen up" mentally. & $2.32(1.41)$ & $3.14(1.71)$ \\
\hline 7. When it comes to my child, I believe in the saying "No pain, no gain." & $1.73(1.17)$ & $2.24(1.42)$ \\
\hline 8. Being injured may help my child "toughen up" physically. & $2.28(1.49)$ & $3.17(1.70)$ \\
\hline $\begin{array}{l}\text { 9. If my child never gets injured he/she is more likely to turn out to be a "wimp" } \\
\text { or "wuss" as an adult. }\end{array}$ & $1.92(1.31)$ & $2.56(1.66)$ \\
\hline $\begin{array}{l}\text { 4. A few minor injuries could be good for my child, because they can help } \\
\text { him/her learn to be more cautious. }\end{array}$ & $4.83(1.47)$ & $5.28(1.39)$ \\
\hline $\begin{array}{l}\text { 5. Experiencing a few minor injuries may help my child prepare better for life } \\
\text { by teaching him/her how injuries occur and can be avoided. }\end{array}$ & $5.13(1.44)$ & $5.42(1.38)$ \\
\hline $\begin{array}{l}\text { 6. Sometimes it is better to let my child learn on his/her own, even if it means } \\
\text { getting hurt a little. }\end{array}$ & $4.91(1.63)$ & $4.80(1.60)$ \\
\hline $\begin{array}{l}\text { 11. When it comes to my child, I believe that "once burned, twice shy" notion } \\
\text { is correct. }\end{array}$ & $4.90(1.40)$ & $5.22(1.32)$ \\
\hline 12. After being injured, my child usually learns not to do the same thing again. & $4.08(1.53)$ & $4.70(1.39)$ \\
\hline $\begin{array}{l}\text { 13. My child's injury experiences help him/her learn the consequences of } \\
\text { risky behavior. }\end{array}$ & $5.08(1.22)$ & $5.32(1.21)$ \\
\hline 14. Getting injured can help my child learn the limits of his/her physical abilities. & $4.21(1.52)$ & $4.35(1.69)$ \\
\hline $\begin{array}{l}\text { 10. My child can build character by taking sensible risks that could result in some } \\
\text { minor injuries (eg, sports). }\end{array}$ & $5.75(1.01)$ & $5.82(1.21)$ \\
\hline
\end{tabular}

Note.

Higher scores indicate greater agreement with the statement.

across mother and father reports, were $.80(\mathrm{P}<.001 ; 95 \% \mathrm{CI}=.66-.85)$ and .77 $(\mathrm{P}<.001 ; 95 \% \mathrm{CI}=.70-.87)$ respectively. Test-retest reliability for the total measure was $.84(\mathrm{P}<.001 ; 95 \% \mathrm{CI}=.77-.90)$. Finally, in order to detect possible differences between those who provided retest data and those who did not, a t-test was performed on the IAQ total scores to compare these groups. The results of this test were not significant.

\section{Descriptive Analyses}

Summing the percentage of responses falling into the "agree somewhat" to "very strongly agree" range for each item in a subscale and dividing by the number of items on that scale revealed that an average of $73.5 \%$ of all participants agreed to some extent with statements about the learning value of injuries. In contrast, an average of $22.4 \%$ of participants responded with some level of agreement to the toughening statements.

Correlations of demographic variables (income, white versus non-white, dualparent versus single-parent household) with parent scores in the IAQ subscales were conducted to determine if parent and/or household characteristics contributed to parents' responses on the IAQ. These correlations were not significant $(\mathrm{P}>.05)$. Mothers' age was also correlated with mothers' scores on the IAQ, and fathers' age was correlated with fathers' scores on the IAQ. These correlations were also non-significant.

Parent and Child Gender Differences

The correlation between mother and father reports for the Learning subscale, Toughing subscale, and the total score was .22 (P<.05), .30 ( $<<.001)$, and .33 $(\mathrm{P}<.001)$ respectively. To further explore 
these relationships, 3 two-way ANOVAs with repeated measures on one factor (parent gender) were conducted to determine if parent gender, child gender, or the interaction of parent and child gender significantly affected reports on the Learning subscale, the Toughening subscale, or the total score. The parent gender $X$ child gender interaction was not significant, nor was the main effect of child gender, for the Learning subscale, the Toughening subscale, or the overall score. However, results did indicate a significant main effect for parent gender for the Learning subscale, $F(1,129)=6.52, P<.05$, the Toughening subscale $F(1,131)=$ $34.61, P<.001$, and the total IAQ score $F(1$, $131)=25.76, P<.001$. The pattern of endorsement was consistent across subscales, such that fathers held stronger beliefs compared to mothers that children learn from injuries $(M=5.11, S D=$ .89; $\mathrm{M}=4.86, \mathrm{SD}=.91$ for fathers and mothers respectively) and toughen up from injuries $(M=3.13, S D=1.36 ; M=$ $2.34, \mathrm{SD}=1.10$ ). This pattern was also consistent with scores on the overall measure, with fathers endorsing stronger beliefs than mothers that children benefit from minor injuries $(M=4.27, S D$ $=.97 ; \mathrm{M}=3.79, \mathrm{SD}=.87$ for fathers and mothers respectively).

\section{DISCUSSION}

The primary objective of this study was to explore parental attitudes regarding the developmental benefits of minor childhood injuries. To accomplish this we first developed the Injury Attitudes Questionnaire (IAQ). This measure contains 2 subscales, one assessing attitudes about the learning value of minor injuries and the other assessing the belief that minor injuries toughen children up. The IAQ demonstrated good internal consistency and 2-week test-retest reliability. Thus, it appears that the scale is assessing a coherent construct and that the level of injury attitudes remains stable over at least a 2-week time frame.

The mean Learning score for all respondents (4.96 out of 7), and findings that $73 \%$ of participants reported some level of agreement with items on that scale, indicate that the great majority of parents support the notion that children learn from their injury experiences. This finding is consistent with a previous survey indicating that parents believe children form opinions about risky behavior from their own injury experiences. ${ }^{4}$ The mean Toughening score of 2.77 suggests that, on average, parents did not strongly endorse the idea that injuries strengthen or toughen children up. However, score distributions across the items showed that a significant minority of parents $(22 \%)$ did respond in the "somewhat agree" to "strongly agree" range on this scale. Thus, although the mean summary score does not indicate strong endorsement by participants as a whole, the response patterns suggest some belief on the part of a subset of caregivers that injuries can toughen children up.

In comparison to mothers, fathers more strongly endorsed the notion that injuries benefit children by toughening them up or teaching them to avoid future injury risk situations. At present, the exact relationship between parent gender and injury beliefs is unclear. However, considering that fathers frequently engage in rough and tumble play with their children ${ }^{12}$ and that men in general engage in more risk-taking behaviors than do women, including those involving physical risks, ${ }^{13}$ it not surprising that fathers appear to more strongly associate children's injuries with potential benefits. In contrast, mothers, who tend to be less tolerant of risk taking, may be more bothered by the potential for serious injury or children's distress when an injury does occur. One possible extension of the current study will be to investigate whether unintentional injuries occur more often during the rough or physical play situations that more often typify fathers' interactions with children (eg, chasing, play fighting, tossing children in the air).

Given past results documenting the differential parental socialization of boys and girls, we were surprised by the $a b-$ sence of a significant child-gender effect or a parent gender by child gender interaction in the present study. It may be that parents of preschoolers view boys and girls similarly with regard to the likelihood they will benefit from their injury experiences. It is unknown, however, whether these similarities are maintained at later developmental periods, when parents may view all children, but especially boys, as better able to withstand injuries. In the context of organized sports, for instance, it is not uncom- 
mon to hear anecdotally of an emphasis placed upon the perceived character-building and toughening-up qualities to be derived from enduring injuries and physical pain. The benefits of minor injuries may be most emphasized in typically male sports (eg, football), which involve a significant amount of rough physical contact. We suspect that replication of this study with parents of older children would be more likely to reveal an effect for child gender.

An important issue worth considering is whether injury experiences do in fact help children learn to avoid later injuries. As noted, it might be logical to suppose that knowledge gained from early injury experiences serves to protect children from similar injuries later. However, it has also been pointed out that the preventive value of early injury experiences may be reduced due to victims' and caregivers' beliefs that injuries are a product of random circumstances and thus are unlikely to recur. ${ }^{14}$ Further, the "once burned, twice shy" assumption fails to consider the possibility that children may successfully engage in a risk behavior multiple (perhaps dozens) of times before and after actually being hurt. This process could weaken or extinguish any deterrent effect that may be operantly conditioned during a single injury event. Finally, empirical studies have shown that children with a previous history of unintentional injuries are at a significantly greater risk of later injuries. ${ }^{15}$ Thus, at present there is reason to question the assumption that injuries serve a significant protective function for children.

Although this study is the first to assess parental beliefs about the potential developmental benefits of minor, unintentional childhood injury, several limitations are worth noting. First, the sample primarily comprises well-educated, white parents from a midsized Midwestern city. This limits the generalizability of findings, which should not be applied to other ethnic groups and parents of lower SES and educational status. Second, one source of recruitment was participants who were already enrolled in the larger injury study. It is possible that such wordof-mouth recruiting may have introduced an unknown degree of bias into the study (eg, through the enrollment of parents with a prior interest in injury prevention). Future work with this measure should include a larger and more representative sample. Finally, the final 14 IAQ items from the original pool of 30 were retained and analyzed based on conceptual similarities to the constructs of interest. Further assessment of the IAQ using statistically driven methods (eg, item analysis) will be important. One objective for future research may be to explore the impact that parental injury attitudes may have on other caregiver behaviors that have a direct bearing on children's safety. It might prove useful, for example, to explore whether injury attitudes are associated with particular parental supervision styles that are more or less protective of children. Clarification of this relationship could reveal viable intervention strategies for working with caregivers who believe-and perhaps act in accordance with-the notion that children learn or otherwise benefit from unintentional injuries.

\section{Acknowledgment}

Support for this study was provided by the National Institute of Child Health and Development (NICHD) Grant \#5R01HD25414-07.

\section{REFERENCES}

1.Dienstbier RA. Arousal and physiological toughness: implications for mental and physical health. Psychol Rev. 1989;96(1):84-100.

2.McMillen C, Zuravin S, Rideout G. Perceived benefit from child sexual abuse. $J$ Consult Clin Psychol. 1995;63(6): 1037-1043.

3.Torell U, Bremberg S. Unintentional injuries: attribution, perceived preventability, and social norms. Journal of Safety Research. $1995 ; 26(2): 63-73$.

4. Morrongiello BA, Dayler L. A communitybased study of parents' knowledge, attitudes, and beliefs related to childhood injuries. Can $J$ Public Health. 1996;87(6):383-388.

5.Clark-Stewart KA. And daddy makes three: the father's impact on mother and child. Child Dev. $1978 ; 49(2): 466-478$.

6. Weinraub M, Frankle J. Sex differences in parent-infant interaction during free play, departure, and separation. Child Dev. 1977;48:1240-1249.

7.Siegel $M$. Are sons and daughters treated more differently by fathers than by mothers? Developmental Review. 1987;7(3):183-209.

8.Jacklin CN, DiPietro JA, Maccoby EE. Sextyping behavior and sex-typing pressure in child/parent interaction. Arch Sex Behav. $1984 ; 13(5): 413-425$.

9.National Institute for Health Care Management. Preventing childhood injuries for a bright future. Action Brief. 2000; August:1-2. 
10.Centers for Disease Control and Prevention, National Center for Injury Prevention and Control. Childhood Injury Fact Sheet (online). Available: http://www.cdc.gov/ncipc/ factsheets/childh.htm. Accessed March 30, 2001.

11.Peterson L, DiLillo D, Lewis $T$, et al. Improvement in quantity and quality of prevention measurement of toddler injuries and parental interventions. Behavior Therapy. 2002;33:271297.

12. Haight W, Parke R, Black JE. Mothers' and fathers' beliefs about spontaneous participa- tion in their toddlers' pretend play. MerrillPalmer Quarterly. 1997;43(2):271-290.

13.Byrnes JP, Miller DC, Schafer WD. Sex differences in risk taking: a meta-analysis. Psychol Bull. 1999;125(3):367-383.

14.Peterson L, Moreno A, Harbeck-Weber C. "And then it started bleeding": children's and mothers' perceptions and recollections of daily injury events. $J$ Clin Child Psychol. $1993 ; 22(3): 345-354$.

15.Jaquess DL, Finney JW. Previous injuries and behavior problems predict children's injuries. J Pediatr Psychol. 1994;19(1):79-89. 